\title{
Washington Cucurto y la literatura del fin
}

\section{Luciano Di Pietro}

\section{(2) OpenEdition}

\section{Journals}

Edición electrónica

URL: https://journals.openedition.org/cher/12296

DOI: 10.4000/cher.12296

ISSN: 2803-5992

\section{Editor}

Presses universitaires de Strasbourg

\section{Edición impresa}

Fecha de publicación: 30 junio 2012

Paginación: 155-165

ISBN: 978-2-35410-046-9

ISSN: 1968-035X

\section{Referencia electrónica}

Luciano Di Pietro, «Washington Cucurto y la literatura del fin», reCHERches [En línea], 8 | 2012,

Publicado el 21 febrero 2022, consultado el 23 febrero 2022. URL: http://journals.openedition.org/ cher/12296 ; DOI: https://doi.org/10.4000/cher.12296

\section{c) (i) (2)}

Ce(tte) œuvre est mise à disposition selon les termes de la Licence Creative Commons Attribution Pas d'Utilisation Commerciale - Partage dans les Mêmes Conditions 4.0 International. 


\title{
Washington Cucurto y la literatura del fin
}

\author{
LUCiano Di PIETRO \\ Université de Perpignan Via Domitia
}

$\mathrm{S}_{\mathrm{f}}^{\mathrm{a}}$ antiago Vega, más conocido como Washington Cucurto, es uno de los fenómenos más importantes de la literatura argentina actual. Nacido en 1973, es, tal vez, el primer escritor negro argentino reconocido. Ya ha publicado más de 10 libros de novelas y poesías entre los que se destacan Cosa de negros, La máquina de hacer paraguayitos, Hasta quitarle Panamá a los yanquis, El curandero del amor y 1810, la revolución vivida por los negros. En los últimos años ha creado una editorial que se llama Eloísa cartonera, que trabaja con el papel y cartón reciclado en las calles por los llamados cartoneros, que son también quienes editan los libros de manera artesanal y con tapas de cartón. Eloísa cartonera ha publicado muchos de sus libros: es solamente con El curandero del amor que entra en una gran editorial (Emecé).

Cucurto lanza una literatura en la cual sus personajes son los inmigrantes dominicanos, paraguayos y peruanos, y en la mayoría de los casos el protagonista es él mismo. Su prosa no respeta las reglas mínimas de la escritura "correcta»: la trama no tiene importancia y se desdibuja con el desarrollo de la novela. Es el anti-policial, en sus novelas no hay ningún misterio que revelar, y el anti-folletín ya que tampoco hay que esperar un final feliz o a veces ni siquiera un claro final. Su estilo es llamado por el mismo autor como "realismo atolondrado", es decir que todo entra a empujones, hay secuencias más o menos largas, flash backs, diálogos directos en los que el autor habla como tal a los lectores. 
La forma de su escritura es una consecuencia de la concepción que Cucurto tiene de la obra literaria: ésta es algo que debe entretener en primer lugar al autor:

Para mí, la literatura es un entretenimiento; el día que me aburra no escribo más. Ya para trabajo tengo mi laburo. La "alta" literatura me aburre. No me gusta cuando se la pone por delante de la vida, cuando cobra un valor trascendental. Prefiero algo más precario. No tratar de escribir superbien, sino buscar una voz propia y trabajar desde otro lugar, una cosa más de pastiche. Esa liviandad me permite meter en juego otras cosas, desde otro lugar. En general escribo rápido, en poco tiempo (Capelli: 2006).

La mayor parte de su prosa y su poesía están enmarcadas en la cumbia y el sexo, desde los cuales nos relata la marginalidad sin escaparle a la política ni a las polémicas literarias. Su prosa y su poesía son chocantes, agresivas. Tomás Eloy Martínez dice que: «Desde Osvaldo Lamborghini no asomaba un lenguaje tan violento, tan fosfórico en la literatura patria» (Cucurto 2009: Contratapa).

Una de las curiosidades es que Washington Cucurto es el personaje principal de la mayoría de las novelas de Santiago Vega, y los libros están firmados con el nombre del personaje. Cucurto puede al mismo tiempo relatar una historia, dirigirse directamente al lector, a su editor o a Santiago Vega: en realidad produce un desdoblamiento de la voz del autor.

La otra particularidad es la cantidad de neologismos que inventa, decimos neologismos ya que no provienen del lunfardo ni de las diferentes expresiones del castellano de los distintos países latinoamericanos sino que son creados por el propio autor o adaptados de lo que escucha:

Yo siempre traté de tomar palabras de la oralidad, escuchar cómo hablaba la gente. La palabra ticki me la decía un compañero de supermercado; yo invento pocas cosas, soy un ladrón claramente. Mi literatura está basada en la oralidad, porque empecé a escribir a partir de lo que escuchaba, de lo que contaba la gente que me rodeaba. Y después también de lo que veía, de los colores, de lo que sentía con la cumbia. Yo sabía que ese mundo no lo conocía nadie, lo viví de muy chico y para mí es un mundo maravilloso (Aletta de Sylas 2010: 64).

Otra cosa a resaltar es que Vega/Cucurto no tiene formación universitaria y trabajaba como repositor en supermercados mientras escribía sus primeros libros de poemas. Sus libros fueron traducidos al inglés y al alemán.

Una de las características significativas de Cucurto es mostrar lo «invisible», en primer lugar los negros. Durante la mayor parte de los dos siglos de vida de la Argentina, los negros pasaron de la esclavitud y la 
marginalidad a una especie de invisibilidad. Según la historia oficial que reinó en Argentina, la mayoría de los negros argentinos habrían muerto en la guerra del Paraguay. Sin embargo, numerosos estudios muestran que siguieron existiendo y muchos también se mezclaron con la población blanca o indígena. El investigador Pablo Cirio saca a relucir el fenómeno de ocultamiento de los orígenes africanos.

Los afroporteños.. se dividen en dos subcategorías. Los negros usted y los negros che. Los negros usted, que son una minoría, son los pocos que lograron una posición de elite económica e intelectual, a fuerza de deshacerse de su lastre étnico y de no comprometerse con su cultura ancestral (y, por lo tanto, de abrazar el ideario blanco de ciudadano). A algunas de esas personas negro usted las conocemos muy bien, porque son personas de la farándula, o de la política, $y$, por una cuestión cultural, nosotros no los podemos ver como negros (y ellos tampoco se reconocen como negros).

-¿Por ejemplo quiénes?

-Vamos a dar nombres. La escritora Griselda Gambaro (afrodescendiente del tronco colonial). El pianista Horacio Salgán. El peluquero Roberto Giordano. La actriz o conductora Carmen Barbieri (Moledo, Olszevicki: 2009).

En Argentina, el mote «negro» se sigue utilizando desde un punto de vista discriminatorio en forma generalizada hacia los pobres. La operación consiste en identificar a una clase social con una raza, ya que en la realidad la mayoría de los pobres son de origen étnico de los pueblos originarios o de diferentes mezclas de aborígenes o negros con blancos. En todo caso, las diferencias de clase reproducen en cierta manera los diferentes tratos que tuvieron las etnias a lo largo de la construcción del Estado argentino. Según el historiador Frigerio:

en la actualidad se puede apreciar la persistente vigencia del término "negros" para hacer referencia, peyorativamente, a los mismos estratos sociales que antes eran denominados "cabecitas negras" y "villeros". Aunque el término no es nuevo ni los reemplaza totalmente, sí los engloba y ha ganado en vigencia. Sugiero, por lo tanto, que por debajo de las implicancias políticas que Ratier adjudica a "cabecita negra" y a las de marginación espacial que podrían inferirse a "villero", la categorización principal que sigue operando es la racial (Frigerio 2006: 12).

Por lo tanto, la existencia de un autor reconocido negro (y que se reivindique como tal) es una novedad en la Argentina, ya que antes era imposible asociar a esa raza con la cultura para el sentido común argentino de clase media.

Otra de las características de Cucurto es su hiperbolismo: sus textos son extremos, sus descripciones son crudas y estilizadas, no tiene pruritos para 
defenestrar personalidades de la cultura o de la historia, exalta partes de la sociedad detestadas por la clase media bienpensante como la cumbia y la prostitución, y el sexo es tomado como un deseo lúdico en el cual no hay una identidad sexual. En Cucurto no hay insinuación, todo es exposición. Graciela Aletta de Sylas sostiene que:

Aceptado este lugar otro, también queremos señalar, que según nuestro criterio, la escritura de Cucurto, tan estrechamente ligada a la referencialidad, no deja lugar a la imaginación ni a la sugerencia. Todo está dicho explícitamente sin dejar ningún margen para que un lector pueda realizar una tarea creativa a partir de un silencio o ambivalencia del texto (70).

Utilizaremos para el análisis de este peculiar escritor tres obras: Hasta quitarle Panamá a los yanquis, El curandero del amor y 1810, la revolución vivida por los negros. Las primeras dos mencionadas son historias de sexo y cumbia, matizadas con denuncia social. Hasta quitarle Panamá a los yanquis es una historia en la que Cucurto (más bien Santiago Vega) escribe sobre las aventuras sexuales (bi-sexuales) de un tal Santiago Vega, repositor de supermercado, quien mientras corre detrás de mujeres y hombres adolescentes, lanza improperios contra el orden establecido y reivindica la inmigración latinoamericana y las razas consideradas inferiores.

El curandero del amor es una novela en la que Cucurto/Vega escribe sobre las andanzas de Washington Cucurto (de quien no nos queda claro si es repositor o escritor) y sus amores extraconyugales con una estudiante de la Facultad de Ciencias Sociales, quien muere y vuelve a aparecer, no se sabe por qué, y finalmente aparece el Curandero del amor, que hace abortos (hace falta recordar que el aborto es ilegal en Argentina) y le pide a Cucurto (el autor y/o protagonista) que lo incluya en su relato. En esta novela el tiempo avanza de manera irregular, en algunas partes avanza 50 años, en otras 500, con situaciones que suceden contemporáneamente.

De las dos novelas recién mencionadas, extraemos algunos párrafos que permitirán mostrar los temas con los que el autor insiste a lo largo de su obra. En primer lugar tenemos la reivindicación clasista racial, que no es hecha de manera ortodoxa. En Hasta quitarle Panamá a los yanquis describe así a los «negros cumbianteros», como los llama él.

Ahí vienen y van al son de la canción, de la dama representante del arte y la música de la raza inferior, quemada, olvidada, explotada por siempre. La responsable de todo, la que paga los platos rotos, las jubilaciones de privilegio y las coimas del senado, ahí, son setecientos, pero representan a quince millones de pobres, setecientos en cada bailanta a lo largo de setecientas 
bailantas, en La Matanza, Lomas del Mirador, Fiorito, Morón, Lanús y todo el Gran Buenos Aires (Cucurto 2005: 16).

En un solo párrafo habla de la postergación histórica de las clases subalternas, de que son quienes deben pagar por los problemas nacionales (la explotación y la corrupción), mezcla a estas clases con la condición racial (la llama raza inferior) y a la vez describe el mundo en el que se divierten, la bailanta, y su geografía, que coincide con el mapa de la pobreza en la periferia de Buenos Aires. Todos estos elementos están insertos en una sucesión caótica, entremezclados en la misma frase. Si esta prosa parece salir del inconsciente es precisamente porque el autor conoce y se siente parte de esa masa marginal. Dice la intelectual argentina Beatriz Sarlo que «a diferencia de Arlt (que escribió ácidamente, rencorosamente contra sus lectores populares, contra sus personajes, implacable en su desprecio), la literatura de Cucurto se ubica a gusto en este mundo» (Cucurto 2009: Contratapa). Al mismo tiempo, tenemos expresiones extremas sobre la justicia que debe existir en una sociedad:

La misma plebe hambrienta tiene que colgarlos, ajusticiarlos con mano propia, y llenar el Congreso con su sangre. ¡Sueño con un Congreso rojo loco, rojo San Martín, Belgrano y Sarmiento! ¡Qué Casa Rosada, negrada, despierten y píntenla de rojo con la sangre de sus dirigentes! (Cucurto 2005: 28)

Este tipo de expresiones no son nada comunes, sobre todo en estos años en los que se habla del fin de las ideologías y el pensamiento único. Frases similares tienen antecedente en la literatura argentina en Roberto Arlt (sobre todo en Los siete locos y Los lanzallamas) o en la pieza de teatro El avión negro (de Cossa, Talesnik, Rozenmacher y Somigliana); la gran diferencia es que fueron escritas en períodos en los que la revolución estaba en el centro de la realidad (en los años 30 y en el 69 respectivamente). En particular, desde el retorno de los gobiernos civiles en 1983, el tema de los escritores de izquierda, es el de la dignidad y no el de la revolución, y si se habla de ésta es desde la nostalgia de una utopía que hoy no se ve en el horizonte cercano.

Otro de los puntos por los cuales Cucurto resulta chocante es por sus constantes referencias a la sexualidad explícita. Pero lo que también sorprende es que sea tomado desde un punto de vista de un placer lúdico en el cual la identidad sexual del protagonista Washington Cucurto sea que le gusta todo. En una secuencia de Hasta quitarle Panamá a los yanquis, hablando de su relación con un paraguayo menor de edad, el autor protagonista dice: 
Dale que pateo para todos lados, juego en todas las posiciones. Dale, para mí el amor no tiene machos ni vencedores, ni culos rotos ni pichas marimachas, dale que para mí el placer no tiene límites ni encarcelamientos. Ni devaluaciones ni corralitos (Cucurto 2005: 21).

En las aventuras con hombres y mujeres del personaje Cucurto, el autor no tiene pudor en hablar de relaciones penadas por la ley, como el sexo con menores. En El curandero del amor cuenta cómo Cucurto, junto a un grupo de escritores, hacen una orgía con niñas. En el inicio de esta escena cuentan el streap tease de una de ellas: "Vero, pelirroja, la más grande de edad por meses, creo que tenía 13. Se levantó la pollera y se sacó la bombacha» (Cucurto 2006: 140). Por mucho menos que ésto, Paul Auster, quien relata el amor de una joven de 17 años con un adulto en el libro Sunset Park, es duramente criticado por la prensa internacional, y en cambio Cucurto no recibe la más mínima objeción sobre este hecho en la prensa argentina. Sobre esto volveremos en el final.

Dentro de su habitual hiperbolismo, Cucurto no tiene pudor en ensañarse con íconos de la cultura: su víctima mas habitual es Jorge Luis Borges. En El curandero del amor dice: "Yo a ese viejo atorrantón y zorro no le creo ni la hora. Como le voy a creer a un ciego que lee, a un tipo que nunca se emborrachó» (139). Pero no se trata solamente de un recurso literario, en una entrevista a la revista Inrockuptibles dice claramente: "Y también es una parodia a ese cuento de Borges "Borges y yo", que me parece una paparruchada total. Borges era un chorro, era bastante berreta, ¿no?» (Capelli 2006).

Entre sus víctimas se encuentra uno de los próceres de la literatura latinoamericana, Pablo Neruda, a quien llama «jmal poeta, farsante y mentiroso!»(Cucurto 2006: 161). En el libro 1810 (que profundizaremos más adelante) también se burla de Borges y Cortázar, escribiendo los apéndices llamados El Phale y Dama tocada, parodiando a El Aleph y Casa tomada respectivamente.

Otra novedad que introduce Cucurto es la escritura del nuevo lunfardo, un argot que hoy en día se nutre de palabras venidas de la inmigración latinoamericana. Y si el argot es otro al histórico, tal vez sea que la Argentina sea otra que la que existía en el imaginario hasta hace algunos años. La investigadora francesa Geneviève Orssaud sostiene que:

L'ensemble de ses écrits le proclame puisqu'ils sont écrits dans un langage américain, en intégrant les argots des immigrés latino-américains à l'espagnol propre à l'Argentine. Il écrit ailleurs : «Nunca me banqué haber nacido en un 
país que se llama Argentina, qué nombre para atrás, tan europeo. Lo primero que haría es cambiarle el nombre a la Argentina: le pondría Panambí, o Añaratamenguá ». C'est toute l'histoire de l'Argentine qui est mise en cause, à près de deux cents ans de l'indépendance du pays (Orssaud 2010: 11).

Y aquí comenzamos con el último, y seguramente el más provocador de todos los libros de Cucurto: 1810, la revolución de mayo vivida por los negros. Y si como dice Geneviève Orssaud, la historia de la Argentina es cuestionada, con este libro lleva el cuestionamiento hasta el final: hasta la ficción. En el prólogo ficcional, en una conversación de Cucurto con Santiago Vega, este último le propone reinventar la historia argentina a su gusto, porque no tiene ninguna garantía de que todo lo escrito sea verificable ya que lo hicieron manos interesadas. En el Manifiesto, antes de iniciar el relato propiamente dicho, Cucurto proclama:

¡Señoras y señores

se acabó!

¡Tomemos la historia por el culo!

¡La historia y la literatura nos pertenecen!

Basta de historiadores de manos blancas

y oscuras ideologías,

ahora la historia la escribiremos nosotros (2009: 12).

Y hablando de los historiadores dice:

Estos señores deben ser juzgados

$\mathrm{y}$ ajusticiados por el pueblo que no sabe

nada de historia,

pues nos contaron una gran mentira:

la historia sostenida en hechos reales,

negándosele el camino a la imaginería y el amor;

como si la verdad tuviera una sola cara:

la del poder.

Y al final, plantea una hipótesis, que se va a transformar en uno de los ejes de la novela:

¿Cuántos de nuestros héroes fueron

terribles hijos de puta?

¿Cuántas calles llevan el nombre de putos ocultos,

héroes silenciados en su ser margarita

convertidos en supermachos por la infamia católica?

O sea, la reinvención de la historia como ficción, como un relato más, partiendo del cuestionamiento de la historia oficial escrita por manos interesadas. Esta recreación toca aspectos no habituales en los libros de historia, pero sí en los libros de Cucurto: el desenfreno sexual, el ataque 
al poder y la destrucción de íconos. En este caso el ícono a destruir (o a reconstruir) es el General San Martín.

1810 nos cuenta que San Martín era un general que se había ido a África en 1790 a reclutar esclavos negros para hacer la revolución en América. En un clima de desenfreno sexual mantiene relaciones con Lorena Cucurtu, que resulta ser la tatarabuela del escritor, quien a la vez también sería descendiente del General. Si bien desde el inicio, José de San Martín es descrito como un hombre orgiástico, son sus palabras de sonámbulo las que revelarán la bisexualidad del prócer: «Soy el General San Martín, poeta y extranjero. Libertador y puto. ¡Me gusta la pija!» (68). Al mismo tiempo, el general practica actividades ilegales: el tráfico de drogas. Conversando con su asistente negro Clodoaldo, el San Martín de Cucurto dice:

- Es una buena, mi general. Los negros ya recolectaron 3500 fardos de la mejor marihuana.

- Muy bien Clodoaldo, olvidá a la negra y cuiden la hierba como oro (49).

Luego San Martín explica las razones de su viaje a África para traer esclavos:

Sólo a ellos se les ocurre vender esclavos de 25 años para arriba, sin dientes, llenos de escorbuto y sarna. ¡Por suerte yo me traje 1600 lolitas y lolitos oscuros de 14 años, merca de primera A total! ¡Sobre ellos construiremos la base de la Revolución del Río de la Plata! (69)

Más tarde, recriminándole su accionar al libertador creado por Cucurto, Lorena Cucurtu, su amante, le dice: «Si, pero al fin y al cabo, no sos más que un milico sudamericano, golpista, represivo, dictador y chorro como todos» (32).

La sucesión de hechos es ubuesca, los negros y San Martín llegan al Río de la Plata en mayo de 1810, y en medio de orgías y cumbia, destituyen al virrey. Si se pensaba que el autor no podía ir más allá en sus exageraciones, leeremos más adelante que Mariano Moreno tiene un clítoris en el ano y que San Martín mantiene relaciones con su hija Merceditas, tan fuerte que hacen vibrar el suelo y el Cabildo salta y estalla por los aires. El final dice que San Martín no se fue a Francia, que es una mentira de los europeístas, sino que su barco se incendió y murió o tal vez se fue a África.

La pregunta entonces es, ¿cómo es que Cucurto puede llegar a tener un auditorio tan importante? Y aquí llegamos a las razones del coloquio.

El tema del coloquio es el fracaso y su reflejo en la literatura latinoamericana. América Latina sufrió durante la década del '90 del neoliberalismo en 
su forma más salvaje. Esto fue la lógica continuidad del fracaso de los intentos revolucionarios en los '70 y las dictaduras que los siguieron, los cuales abrieron paso a gobiernos electos que siguieron las mismas políticas económicas de los militares del Plan Cóndor. La caída del Muro de Berlín ha difundido en el mundo el llamado "pensamiento único», o sea, que el capitalismo no tiene alternativas. Este movimiento ha provocado una gran decepción en el campo intelectual llamado de izquierda. La Argentina de los '80/90 se encuentra con dos fracasos: el fracaso de la revolución y el fracaso de la patria.

El concepto de patria en Argentina estaba muy ligado a las fuerzas armadas, ya que es un país que se tuvo que independizar combatiendo: el ejército argentino existe desde antes de la declaración de la Independencia. El sujeto social que la llevó adelante como líder, a diferencia de la descolonización de los países africanos o asiáticos en el Siglo XX, no son los pueblos originarios sino los descendientes de los colonos, los llamados criollos: blancos y descendientes de españoles. Para decirlo con una expresión francesa, son los pieds noirs criollos los que toman las riendas del país.

Esta idea de país, dominado por la elite blanca y con los militares como portaestandartes de la patria, llega a su fin en 1982 con la derrota en la Guerra de las Malvinas. Si todas las atrocidades hechas por los militares y las llamadas fuerzas del orden (desapariciones, torturas, robos) durante decenios se habían hecho en nombre de la patria, cuando se trataba de defender una causa nacional hicieron defección. Y para el pueblo argentino fue insoportable: de golpe los militares eran los culpables de todos los males de la Argentina (Di Pietro 2010). Del otro lado, el aplastamiento físico de la generación combativa de los '70 y el hecho de que los militares no hayan caído por las luchas populares, sino por una derrota contra las grandes potencias, aleja a los revolucionarios como alternativa al poder en Argentina. Con lo cual tenemos en Argentina dos derrotados, la revolución y las conocidas como fuerzas del orden, o sea que pierden un enorme prestigio la autoridad moral (de los revolucionarios) y la autoridad real (la policía y fuerzas armadas).

En los '90, con el saqueo neoliberal de Menem y De la Rúa, se abren los espacios para que aparezcan autores «descreídos» que no dudan en poner en cuestión todo. Dentro de la literatura, el principal es el autor que nos ocupa, Washington Cucurto. Para enmarcar el contexto de los valores argentinos actuales, el novelista Carlos Gamerro escribe el ya famoso decálogo del relato 
policial argentino, en donde se aprecia que los valores y el imaginario de la población argentina, ya no son los herederos de la «patria sanmartiniana»:

\section{Decálogo del relato policial argentino}

1. El crimen lo comete la policía.

2. Si lo comete un agente de seguridad privada o -incluso- un delincuente común, es por orden o con permiso de la policía.

3. El propósito de la investigación policial es ocultar la verdad.

4. La misión de la Justicia es encubrir a la policía.

5. Las pistas e indicios materiales nunca son confiables: la policía llegó primero. No hay, por lo tanto, base empírica para el ejercicio de la deducción.

6. Frecuentemente, se sabe de entrada la identidad del asesino y hay que averiguar la de la víctima.

7. El principal sospechoso (para la policía) es la víctima.

8. Todo acusado por la policía es inocente.

9. Los detectives privados son indefectiblemente ex-policías o ex-servicios. La investigación, por lo tanto, sólo puede llevarla a cabo un periodista o un particular.

10. El propósito de esta investigación puede ser el de llegar a la verdad y, en el mejor de los casos, hacerla pública; nunca el de obtener justicia (Gamerro 2008).

Como podemos apreciar, los valores que rigen la estética en la Argentina de hoy no son los tradicionales. Con la revuelta del 2001 se pone en cuestión inclusive la democracia, ya que se vuelve legítimo derrotar en las calles a un presidente elegido por los votos si no cumple con sus promesas. Con esto, pese a la caída del llamado «socialismo real», los revolucionarios, en particular aquellos de los ' 70 , vuelven a tener una visibilidad y un auditorio, sin que por ello se refuercen automáticamente como contrapartida las fuerzas de represión. En este contexto, adquieren visibilidad problemas históricos irresueltos como ser los pueblos originarios, los negros, los homosexuales; éstos reivindican sus derechos en alta voz y a veces hasta obtienen conquistas, como el matrimonio homosexual votado recientemente.

Es este el marco social que permite la emergencia de Cucurto: no es verdad que sólo en circunstancias similares puede nacer un Cucurto, pero sí que este marco permite la existencia de un público permeable como para que este tipo de autores alcancen la popularidad. La caída de la moral autoritaria es un fenómeno que llegó para quedarse en Argentina: ya nadie puede creer 
que se asesina por la patria después de la ESMA y Malvinas, nadie puede proclamarse defensor de la moral ya que este argumento fue utilizado con los más oscuros fines en los años de la dictadura. Hoy nadie puede asustarse porque un escritor negro insulte a San Martín y Borges, reivindique la cumbia y las relaciones bisexuales lúdicas.

Contrariamente a lo que opinan algunos pseudo-eruditos, Cucurto no es el fin de la literatura : es la literatura del fin. Del fin de la Argentina blanca y racista creada bajo el mito sanmartiniano en el cual los militares eran los baluartes de la patria y la moral católica su compañera inseparable. En la Argentina actual todo está por reconstruirse y Cucurto es un ladrillo de esa construcción novedosa.

\section{Bibliografía}

Cucurto, Washington, 2009, 1810, la revolución vivida por los negros, Buenos Aires, Emecé.

Cucurto, Washington, 2006, El curandero del amor, Buenos Aires, Emecé.

Cucurto, Washington, Hasta quitarle Panamá a los yanquis, 2005, Buenos Aires, Eloísa cartonera.

Aletta de Sylas, Graciela, 2010, «El lenguaje de la marginalidad en Paraguayito de mi corazón», en Políticas lingüísticas, año 2 vol. 2, Córdoba, Universidad de Córdoba.

Capelli, Matías, 2006, Borges era un chorro, entrevista a Washington Cucurto, Buenos Aires, Revista Inrockuptibles $\mathrm{n}^{\circ} 110$.

Di Pietro, Luciano, 2010, El concepto de patria antes y después de la guerra de las Malvinas (inédito), en vías de publicación por la Université de Perpignan.

Frigerio, Alejandro, 2006, «Negros y Blancos en Buenos Aires: repasando nuestras categorías raciales», in Temas del patrimonio cultural, Buenos Aires, Comisión para la Preservación del Patrimonio Histórico Cultural de la Ciudad de Buenos Aires.

Gamerro, Carlos, «Disparen sobre el policial negro», in Diario Clarín, 13/8/2008, Buenos Aires.

Moledo, Leonardo, Olszevicki, Nicolás, «El argentino no está preparado para ver a los negros», entrevista a Pablo Cirio, in Diario Página/12, 27/7/2009, Buenos Aires.

Orssaud, Geneviève, 2010, «Pop argentino», in Trans - Revue de Littérature Générale et Comparée, Hiver, Paris, Université Paris III. 